\title{
Consequences of Moral Transgressions: How Regulatory Focus Orientation Motivates or Hinders Moral Decoupling
}

\author{
Kirsten Cowan ${ }^{1} \cdot$ Atefeh Yazdanparast ${ }^{2}$
}

Received: 25 June 2018 / Accepted: 16 August 2019 / Published online: 4 September 2019

(c) The Author(s) 2019

\begin{abstract}
How can firms mitigate the impact of moral violations on consumer evaluations? This question has pervaded the business ethics literature. Though prior research has identified decoupling as a moral reasoning strategy where consumers separate moral judgments from evaluations (avoiding moral compromise and dissonance), it is unclear what motivates individuals to decouple. It is the objective of this research to explore regulatory focus theory (i.e., a framework examining consumer mindsets as prevention or promotion orientated) as a motivating factor for moral decoupling. Three experiments are undertaken. Study one demonstrates that with a prevention mindset (e.g., analytical thinking) as opposed to promotion mindset (e.g., feeling-based thinking), moral decoupling can be achieved. Specifically, those in a prevention mindset report more favorable evaluations when information about a violation explicitly lowers (vs. does not lower) consequences of moral violations. However, when the violation is related to the business functionality of the brand, those in a prevention (vs. promotion) mindset report less favorable evaluations, except when consequences are lowered. This indicates an inability to decouple (studies 2-3), and results in negative emotions (study 3). The research shows that inability to decouple for those in a prevention mindset leads to negative emotions, lowering evaluations. These results contribute to the moral reasoning literature by linking regulatory focus to decoupling strategies. Further, the research bridges literature on norm activation, moral foundation, regulatory focus, and moral decoupling to reconcile theoretical differences in judgment styles. Implications for businesses and brands are discussed.
\end{abstract}

Keywords Moral reasoning $\cdot$ Moral decoupling $\cdot$ Moral foundations $\cdot$ Regulatory focus $\cdot$ Political brands $\cdot$ Consumer judgment

\section{Introduction}

People regularly encounter news, especially negative news, about brands and businesses (Diermeier 2012; Trump 2014). Moral violations, a prime example of negative news, refer to actions deemed unacceptable with regard to generally accepted norms of behavior (Reynolds 2006; Treviño et al. 2006). These violations are normally organized in

Kirsten Cowan

Kirsten.COWAN@ed.ac.uk

Atefeh Yazdanparast

ay42@evansville.edu

1 Business School, University of Edinburgh, 29 Buccleuch Pl, Edinburgh EH8 9JS, UK

2 Schroeder School of Business Administration, University of Evansville, 1800 Lincoln Ave., Evansville, IN 47722, USA peoples' minds by assigning a victim role to the consumers (or society) and a perpetrator role to the brand (Romani et al. 2015). While some instances of brand moral violations have resulted in purchase boycotts or unfavorable evaluations (e.g., protests against Burberry for using hazardous chemicals), other instances exist where no or mixed evaluations occurred. For example, in December 2017, nearly "no one" deemed Nike as negative. Yet, after Nike used Kaepernick (i.e., an athlete who refused to stand for the national anthem), around $17 \%$ of people viewed Nike negatively (Street-Porter 2018). Kaepernick might not have caused this change in perceptions, but his actions could have been a contributing factor. As a political brand, Bill Clinton had an extramarital affair and was impeached, though was elected to a second presidential term. More recently, the Chinese firm Huawei, a global leader in the manufacturing of mobile phone network equipment, has stirred much debate about espionage. Several companies and firms have blocked 
Huawei while the UK argues that these issues can be mitigated (Huawei 2019). As these examples imply, moral violations force people and business partners to decide whether or not they will continue relationships with transgressors. What explains such differences in reactions to moral violations?

The morality literature identifies moral reasoning strategies that people use to allay negative moral judgment, including moral rationalization (Mazar et al. 2008; Paharia and Deshpande 2009; Shu et al. 2011) and moral decoupling (Bhattacharjee et al. 2012). Moral rationalization occurs when people support a transgressor by interpreting the immoral action as less immoral (e.g., the moral violation is unimportant). Decoupling, though, dissociates immoral judgments from job-related performance judgments (e.g., his actions were immoral but his athletic performance is positive). Because all moral judgments link closely to the selfconcept, people try to maintain a positive view of themselves in terms of their moral standards. As such, rationalizing immoral behavior to maintain support for the transgressor could result in compromising one's moral standards, which yields tension (Thøgersen 2004). Moral decoupling, though, feels better than rationalization (Bhattacharjee et al. 2012) and prevents dissonance (Lee et al. 2016).

It is still unclear whether decoupling occurs. Some researchers suggest decoupling is less likely given the lack of well-supported empirical evidence (e.g., Stellar and Willer 2018). Others posit that decoupling occurs when consumers identify more strongly with the business (i.e., brand love, self-brand connection, etc.; Lee et al. 2015) or when the immoral act is unrelated to job performance (e.g., performance-enhancing drugs as a political figure versus a cyclist; Lee and Kwak 2016). Still, decoupling may be harder to trigger in situations where performance is subjective, such as politics (Bhattacharjee et al. 2012). As such, more research is needed (e.g., Bhattacharya and Elsbach 2002; Hoegg and Lewis 2011) to better understand decoupling. Specifically, within the business ethics literature, extant research fails to provide an explanation for who engages in decoupling and when it occurs. Moreover, it is unclear how consequences of violations impact decoupling. In other words, individual and contextual factors may motivate individuals to decouple. The present research focuses on regulatory focus as a motivational approach to explain how people process and interpret immorality.

We hypothesize that moral judgments stem from consumers' motivation to process information, such as that emphasized by regulatory focus theory. This theory is able to explain differences in decision-making and judgment, activated by a promotion (i.e., pursues goals, uses feelings and emotions) or prevention (i.e., avoids losses, uses cognitions, and risk evaluations) mindset (Higgins 1997, 1998; Roy and Phau 2014). Under regulatory focus theory, we argue that promotionfocused consumers cannot separate moral judgments from other information, such as consequences of the moral violation. This is consistent with research demonstrating that people often disregard factual information about the consequences of the violation, relying on emotion and intuition (Bloom 2013; Haidt 2001). We also predict that those in a prevention mindset can separate moral judgments from evaluations, such as when a moral violator reduces consequences to others resulting in less-negative moral judgments. This argument, though contrary to Haidt (2001) and others, is in line with other morality theorists (e.g., Schwartz 1977), suggesting that negative evaluations follow moral violations when consequences exist.

In sum, we argue that those in a prevention (vs. promotion) mindset are more likely to use moral decoupling. However, in line with moral decoupling literature, we argue that in a prevention mindset, it should be more difficult to separate moral judgments from performance judgments when a transgression is directly related to job performance (e.g., taking steroids as a cyclist). Violations related (vs. unrelated) to performance should serve as a boundary condition. Thus, the primary objective of this research is to answer the following questions. Does regulatory focus influence how consequences of moral violations determine consumer evaluations? Are moral violations related to job performance judged differently? And, do negative emotions explain the tensions experienced in moral reasoning?

To that end, three experiments support our hypotheses that moral violations are more damaging when individuals have a promotion (vs. prevention) mindset, unless the violation relates to the transgressor's job performance (studies 1-3). Moreover, moral violations related to job performance are more negative when individuals have a prevention (vs. promotion) mindset and potential consequences to the transgressor are high (studies 2-3). Lastly, negative emotions underlie these effects (study 3), supporting regulatory focus as motivating moral decoupling. This research offers several noteworthy findings. First, it identifies regulatory focus theory as a relevant motivational theory, which can lead to or hinder decoupling strategies. Second, the research reconciles prior theorizing on morality literature, demonstrating that some consumers (i.e., those with a promotion mindset) use emotions to judge moral violations and are incapable of separating consequences of moral violations from brand evaluations (e.g., Haidt 2001). Though, others (i.e., those with a prevention mindset) integrate consequences in their judgments (e.g., Schwartz 1977). Lastly, we provide practical implications for businesses and brands.

\section{Theoretical Background}

\section{Morality and Moral Foundations Theory}

Morality, a significant foundation for people's self-concepts, is a motivating force in society, which influences attitudes, 
values, and purchase intentions (Weiss 1942). Moral systems are "inter-locking sets of values, practices, and evolved psychological mechanisms that work together to suppress or regulate selfishness and make social life possible" (Haidt 2008 , p. 70). The morality of a society is, thus, related to its social customs as being the right and wrong ways to act, as well as to the laws of the society which add legal prohibitions and sanctions to many activities considered immoral (De George 1987). According to Walzer (1983), the morality of a society is gradually built up from the specific experiences of the community in dealing with specific cases (i.e., judgments of actions).

Moral foundations theory was developed to explain how morals differ across cultures. The theory identifies six foundations for human behavior and moral judgment (Graham et al. 2011), namely care (i.e., care for and protect others, avoid harm), fairness (i.e., justice for all, avoid treatment of inequality), liberty (i.e., freedom for all, avoid oppression), loyalty (i.e., patriotism and loyalty to groups which we belong, avoid selfishness), purity (i.e., respect for religious tradition, avoid degradation), and authority (i.e., acceptance of hierarchy, avoid disobedience; Haidt and Joseph 2004). The type of foundation violated determines the extent of negative judgment. Care, liberty, and fairness are individualizing, focused on protection and fair treatment of all. Though, loyalty, authority, and purity are binding, promoting binding individuals to larger groups such as a family, nation, or religious organizations.

\section{Moral Judgment and Reasoning}

Deviation from societal customs and laws can also be explained by the Norm Activation Model (NAM; Schwartz 1977), which includes three variables related to morality. The first, personal norms (PN), refers to feeling a moral obligation to engage in or prevent behaviors (Schwartz and Howard 1981). The second variable relates to the awareness of negative consequences (AC) for others when acting immorally. Third, ascription of responsibility (AR) pertains to the degree of felt responsibility for the negative consequences (i.e., whose fault it is when immorality leads to negative consequences). AC of immoral behavior results in AR (De Groot and Steg 2009). For example, when a politician supposedly has an affair, people who believe that society will become more corrupt as a result will ascribe more responsibility of the behavior to the politician (White et al. 2009). This is further evinced by studies showing that AC affects AR, and AR affects feelings related to PN (Steg et al. 2005).

Generally, moral judgments emerge when three causally interconnected components are present: norm violation, negative affect, and harm. Norm violations are negative and may prompt perceptions of harm that lead to negative affect (Schein and Gray 2018). And yet, people can engage in strategies to attenuate negative affect, such as moral rationalization, moral reasoning approaches that justify or excuse immoral actions to make them personally acceptable (Bandura 1999). Rationalization tends to focus on a person's beliefs. For instance, individuals, when rationalizing, can redefine the harmful behavior, minimize the violator's role in causing harm, blame the harmed, or minimize or distort harm caused by the violator. Employing these strategies, however, compromises one's moral standards in order to condone immorality (Mazar et al. 2008; Paharia and Deshpande 2009; Shu et al. 2011).

Another strategy, less likely to result in compromise with the self-concept, includes moral decoupling, which separates immoral behavior from the performance of the transgressor. This strategy works by altering the manner of viewing a moral action as associated with performance in a given domain. In a series of studies, Bhattacharjee et al. (2012) provided evidence that decoupling boosts brand support but also condemns the transgressor's immorality. Thus, decoupling, compared to rationalization, feels easier to justify and results in predictable support and opposition of transgressors. However, decoupling may be more difficult to employ when the immoral act is related to the transgressor's job performance (Lee and Kwak 2016). Despite these significant insights, it is not yet clear if all individuals employ moral decoupling (as opposed to moral rationalization) when facing a moral judgment task, and if not, what individual or situational factors impact such decisions. For instance, it is not clear if the type of moral violation (i.e., moral foundation type), the level of consequences of the moral violation, and the motivational ability of individuals to process moral violation information have an impact on moral decoupling.

Given the different information available regarding consequences of moral violations and types of moral foundation violation, it is important to examine how people process this information. As such, we focus on the motivational dynamics underlying moral evaluations. Due to the subjective nature of political performance, we selected this context to examine moral decoupling strategies as related to job performance in a more ambiguous situation (Bhattacharjee et al. 2012). This approach enables us to understand how people can separate consequences of a moral violation from individual conduct to mitigate negative judgments. Additionally, a political context enables critical evaluation of the role of awareness of moral violation consequences (AC) in shaping moral judgments (cf. De Groot and Steg 2009). Finally, it will aid in providing theoretically sound explanations for how some people can disregard moral information when judging a brand, while others base their judgments on moral information.

In doing so, we focus on violations related to purity and authority foundations for several reasons. First, despite their differences, purity and authority-related moral issues are 
consistent with scenarios politicians are frequently accused of violating (Diermeier 2012). As a case in point, consider the accusations against President Trump, mainly focusing on sexual relationships and obstruction of justice. Second, these two binding moral foundations have not been studied in modern research with respect to moral evaluations. Following a systematic review of extant research on immoral behaviors in top marketing journals, Komarova Loureiro et al. (2016) found no research examining authority and purity immoral behaviors, arguing that these moral foundations "have been virtually neglected" (p. 4). So, the present research fills a gap in the literature by examining the prescriptive nature of authority and purity moral violations (Janoff-Bulman et al. 2009). Third, since the consequences and the scope of impact of violations related to binding moral foundations go beyond the individual and his/her immediate circle and expand to the larger groups, organizations, and society (Graham et al. 2009), it is important to examine how violations are evaluated by members of the society. Such an approach is warranted given the fact that people are more willing to engage in deviant behavior if they are exposed to immorality, a phenomenon called moral spillover (Mullen and Nadler 2008). A focus on purity and authority violations allows an empirical examination of these binding moral foundations in Western society. Fourth and relatedly, given prior arguments suggesting that Western societies are less likely to emphasize adherence to binding moral foundations (Haidt and Joseph 2004; Shweder et al. 1997), the present research examines these claims in a political context, because political actions affect society at large.

\section{Regulatory Focus Theory and Morality Judgment}

Regulatory focus is a higher-order motivational goal that activates different mindsets, influences the choice of information used in decision-making, and accounts for consequences in actions (Roy and Phau 2014). Specifically, regulatory focus theory argues that people have a promotion or prevention mindset (Higgins 1997, 1998). When experiencing a prevention mindset, individuals focus on duties and obligations, look for safety, and minimize consequences in their decisions. In a promotion mindset, though, individuals are motivated to accomplish their hopes and dreams and improve their situation (Crowe and Higgins 1997; Higgins 1997, 1998). Different mindsets guide information choice in judgment and decision-making, such as brand evaluations (Roy and Phau 2014).

Extant research shows that promotion and prevention mindsets prompt different mental approaches that result in different information processing styles (Wang and Lee 2006). Neuroimaging research indicates that induction of a promotion mindset activates the frontal regions of the brain, while a prevention mindset activates posterior regions (Packer and Cunningham 2009). As a result, people experiencing a promotion mindset employ abstract or relational information processing, while people in a prevention mindset use concrete or item-specific information processing (Smith and Trope 2006; Roy and Phau 2014; Förster and Higgins 2005). While relational elaboration involves integration and abstraction and focuses on overall relationships among information elements, item-specific elaboration involves separate and context-specific evaluation, focusing on each information element/attribute independent of others (Zhu and Meyers-Levy 2007).

Given the processing styles activated, regulatory foci can influence judgments of moral violations and result in varying evaluations. For instance, following an itemspecific information processing, people in a prevention mindset are expected to assess information about the moral violation and its consequences independent from each other. This is in line with prevention mindset tendency to prevent negative consequences and attend to risk (consequences) information (Higgins 1997, 1998). Additionally, a prevention mindset is associated with deliberative, analytical reasoning (Pham and Avnet 2004, 2009), use of external sources of information (Bless et al. 1992, 1996), and accurate decision-making (Förster et al. 2003). Thus, individuals in a prevention mindset should use PN, $\mathrm{AC}$, and $\mathrm{AR}$ to make decisions such that when $\mathrm{AC}$ is low, judgement should be less negative.

However, a promotion mindset should help individuals process information about a moral violation holistically, based on ideals and aspirations (Higgins 1997, 1998). In fact, promotion mindset places a greater reliance on feelings, heuristics (Pham and Avnet 2004, 2009), intuition, internal sources of information (Bless et al. 1992, 1996), and rapid decision-making (Förster et al. 2003). Because they analyze information abstractly and use feelings in judgement, we expect individuals in a promotion mindset to report similar evaluations, regardless of AC. We propose, therefore, that $\mathrm{AC}$ should interact with regulatory focus orientation to influence individuals' evaluations. Whereas having a prevention mindset should attenuate the impact of moral violations on judgments as long as $\mathrm{AC}$ is low, having a promotion mindset will not. In fact, when overtly lowering AC (e.g., specifying that consequences to the brand are mitigated), those in a prevention mindset should evaluate the transgressor less negatively than those in a promotion mindset do. Formally:

$\mathrm{H}_{1}$ Moral violation AC and regulatory focus orientation interact to influence evaluations, such that regardless of type of moral violation, evaluations will be less negative for those in prevention mindset when $\mathrm{AC}$ is low (vs. high). For those in a promotion mindset, however, such results are not expected. 


\section{Relatedness to Job Performance}

When moral violations are central to the brand performance, individuals should evaluate the violation more negatively. Though not investigated with regard to regulatory focus, some moral violations have been found to be less damaging than others (Bertolotti et al. 2013; Effron et al. 2015; Laurent et al. 2014; Lee et al. 2015). More specifically, when violations are unrelated (as opposed to related) to the transgressor's job performance, individuals are more likely to engage in moral decoupling strategies (Lee and Kwak 2016). For instance, in the case of athlete endorsers' immoral behaviors, when the transgression is highly relevant to an athlete's job performance (e.g., use of performance-enhancing drugs) versus unrelated to job performance (e.g., fraud), people are less likely to engage in moral decoupling and will have less favorable brand evaluations (Lee et al. 2015). Thus, moral violations related to the job performance of a transgressor are expected to be more harmful for the brand regardless of the regulatory focus. Formally:

$\mathrm{H}_{2}$ Regardless of the evaluator's regulatory focus, a moral violation that is related (vs. unrelated) to job performance will result in lower brand evaluations.

The aforementioned discussion argues for the moderating role of regulatory orientation in the relationship between the moral violation type and consumer evaluations. Drawing on regulatory focus theory and given the nature of regulatory orientations, we believe that for those in a promotion mindset, relatedness of the moral violation is not a concern, as these individuals do not process information in a contextspecific manner (Zhu and Meyers-Levy 2007; Förster and Higgins 2005); rather they assess the situation as a general moral violation case. On the other hand, those with a prevention mindset examine the consequences to the brand more critically, given their tendency to process context-specific/ local information (Higgins 1997, 1998). As such, when the violation is related (vs. unrelated) to the brand performance, we expect these individuals to perceive greater (lesser) damage to the brand, and evaluate the brand more (less) negatively. When the moral violation is related to a brand's job performance, it should be more difficult for preventionoriented individuals to dissociate moral judgments from performance. For example, if a cyclist took performanceenhancing drugs, it is more difficult to separate the judgment of the cyclist as an athlete from the moral misdeed, because his moral violation is tied to his job performance. In other words, the judgements are inseparable, and decoupling is not possible.

When decoupling is not feasible, other moral reasoning strategies (e.g., moral rationalization, moral coupling, etc.) more likely occur. As opposed to decoupling, these alternative strategies yield tension and negative emotions for the evaluator (Thøgersen 2004; Lee et al. 2016). As such, prevention-oriented individuals' inability to exercise moral decoupling will result in negative emotions. However, when the moral violation is not directly related to the brand's job performance, decoupling would be easier and thus, individuals will be able to maintain a positive view of themselves and their moral standards. Consequently, less-negative emotions are experienced. Thus, we predict that negative emotions underlie the judgments for these interactions.

The role of emotions in moral judgment has been a topic of debate for centuries (Cannon et al. 2011). Some philosophers (e.g., Immanuel Kant) followed a rationalist view to moral judgments and saw little role for emotions in judgments of morality. Other philosophers (e.g., David Hume), however, believed that emotions drive moral judgments. This view has been further developed in contemporary psychological theories, suggesting a central role for emotions in moral judgments. Extant research has provided support for the existence of negative emotions such as anger and disgust with respect to moral violations (Chan et al. 2014; Starcke et al. 2011; Romani et al. 2015). Recent findings suggest that moral judgments relate more with emotions than deliberate reasoning (Greene and Haidt 2002; Teper et al. 2015). Yet, the underlying role of such emotional experiences in firm or brand evaluations has not been examined.

The mere feeling of emotions can trigger an approach or avoidance behavior (Labroo and Rucker 2010). Positive emotions activate approach behavior and result in optimistic evaluations of risk and consequences. Negative emotions, however, lead to avoidance, delayed decision-making, outright refusal to making decisions (Anderson 2003; Luce 1998; Luce et al. 2000), and pessimistic evaluations (Johnson and Tversky 1983). Interestingly, negative emotions can enhance perceptions of risk and consequences (Lerner et al. 2003) because they are more closely linked to risk judgements (Slovic 1987). Relatedly, negative emotions evoke thoughts of impending negative consequences and heighten feelings of negative outcomes (Carver and Scheier 1998; Schwarz and Clore 1983), lowering evaluations (Griskevicius et al. 2009; Lee and Andrade 2011; Lerner and Keltner 2001; Raghunathan and Pham 1999).

Thus, in the specific case of moral judgements and as discussed earlier, prevention mindset individuals' inability to exercise moral decoupling for moral violations related to brand's job performance (and thus, relying on less preferred moral judgment strategies) results in experiencing negative emotions. In turn, this causes more pessimistic evaluations of the brand (Smith and Trope 2006; Roy and Phau 2014; Förster and Higgins 2005). Thus, we predict that for individuals with a prevention mindset, negative emotions will underlie differences in brand evaluations between violation types. Formally: 
$\mathrm{H}_{3}$ There will be an interaction between moral violation type and regulatory focus on brand evaluations, such that brand evaluations will be less negative for prevention (vs. promotion) mindsets when the brand does not violate a performance-related moral foundation. In a promotion mindset, however, we do not expect the moral violation type (performance-related or not) to make a difference.

$\mathrm{H}_{4}$ Negative emotions mediate the relationship between the interaction of moral violation and regulatory focus orientation on brand evaluations.

\section{Overview of Studies}

The present studies investigate a novel possibility that people with a prevention mindset can separate moral judgment from brand judgment, potentially employing a moral decoupling strategy. Investigating this issue, the research distinguishes two alternative explanations, namely moral decoupling and individual political orientation. A political orientation account suggests that individual judgments stem not from motivational characteristics but from individual attitudes (e.g., Iyer et al. 2012; Graham et al. 2009), where liberals (vs. conservatives) judge a binding morality violation, such as a purity violation, less negatively. Given that morality research has investigated individuals' political orientations within general, non-political contexts, it would be relevant to examine this alternative explanation within a political business context. Alternatively, a regulatory focus account predicts that individuals with a prevention mindset will judge a brand less negatively if consequences (i.e., AC) are low (versus high). This would provide initial support that having a prevention (vs. promotion) mindset could motivate individuals to engage in moral decoupling strategies, enhancing brand evaluations.

Along these lines, we investigate how regulatory focus orientation and $\mathrm{AC}$ interact to influence brand evaluations, while simultaneously measuring individual political orientation. Given that moral decoupling involves separating personal judgments of the moral act from judgments of the brand, we predict that individuals with a prevention mindset are more likely to exhibit moral decoupling. Specifically, we expect individuals with a prevention mindset to judge a brand less negatively provided (vs. not provided) assurance of low AC. However, the type of violation will serve as a boundary condition, making it harder for those in a prevention mindset to morally decouple when the misdeed is related to the brand's job performance.

Three studies provide empirical support for the proposed moral decoupling explanation and reject the alternative account of individual political orientation since political orientation neither influences brand evaluations in several studies nor changes how regulatory focus and AC inform brand evaluations. Study 1 provides evidence that those in a prevention mindset can decouple when AC is low (vs. high). Study 2 extends these findings with a performance-related (e.g., authority) violation. This study offers new evidence that a prevention mindset's decoupling abilities could be hindered when AC is high (vs. low) for performance-related scenarios. Finally, Study 3 compares the violation types under high AC and offers further evidence for the boundary effect of violation type (in terms of its relevance to performance). The results provide further insights about situations where decoupling is hindered, resulting in negative emotions that mediate the interactive effect of violation type and regulatory focus on brand evaluations.

\section{Method}

Before conducting the main studies, a pre-test, inspired by Haidt and colleagues, was run to create AC conditions and authority and purity violation scenarios for the main studies within a political brand context. A sample of $(n=56)$ business professionals, marketing practitioners, and academics were exposed to one of four conditions (see "Appendix A: Moral Violation Scenarios"): purity violation with high $\mathrm{AC}$, purity violation with low $\mathrm{AC}$, authority violation with high $\mathrm{AC}$, and authority violation with low AC. Then, they were asked to report the violation type ("Please indicate the degree to which you agree that the risk in the scenario concerns a(n) purity (authority) violation"; Shweder et al. 1997) and the consequences ("The scenario does not include any risks to Charles Johnson or others"). All items used a Likert-type scale, where $1=$ strongly disagree and $7=$ strongly agree. A single $t$ test (test value $=4$ ) was used to assess the viability of scenarios. The $t$ test revealed that all participants who read the purity scenario considered it related to purity $(M=5.00, \mathrm{SD}=2.16 ; t=2.02, p<0.03)$. Likewise, those who read the authority scenario considered it related to authority $(M=4.65, \mathrm{SD}=1.62 ; t=1.65, p=0.05)$. Next, a one-way ANOVA compared the AC perceptions and revealed that consequences were significantly lower in the low (vs. high) AC scenario $(M=2.30, \mathrm{SD}=1.64$ vs. $M=4.43, \mathrm{SD}=2.15$, respectively; $F(1,55)=5.40 ; p<0.04)$, supporting the scenarios.

Given that the aim of the pre-test was to test the appropriateness of the scenarios, the pre-test results are limited to a professional sample. Therefore, two follow up pretests were run to establish the viability of the scenarios for the target population. First, a pre-test for the authority scenario was run using a sample of 64 U.S. citizens $(51 \%$ male; $M_{\text {age }}=41$ years) on Mturk. The study manipulated AC on two levels (low vs. high), identical to the previously created scenarios. After random assignment to one 
of the AC levels, participants responded to nine sevenpoint semantic differential items reflecting, "How would you describe the actions of Charles Johnson as described in the scenario?" with four morality items embedded in a list of nine descriptors (immoral/moral; bad/good; incorrect/correct; unacceptable/acceptable; $\alpha=0.92$ ) and one of the items measuring $\mathrm{AC}$ (risky/not risky-reverse coded subsequently so that high scores indicated higher perceived consequences). Next, they responded to, "How much do you think the situation is concerned with the following?" for each of purity standards (respect for religious traditions), loyalty towards a group, caretaking, and undermining authority (where $1=$ not at all, $7=$ very much).

An ANOVA with AC $(0=$ low, $1=$ high $)$ as the independent variables revealed no effect on perceptions of morality $(F<1)$ or authority. Importantly, a single $t$ test (test value $=4$ ) was used to assess the relevancy of the scenarios for investigating morality and the scenario as authority-related. The $t$ test revealed that all participants considered the scenarios more closely related to immorality $(M=3.47, \mathrm{SD}=1.25 ; t=-3.24, p<0.01)$, offering support that the authority scenarios reflect immorality, and related to authority $(M=4.80, \mathrm{SD}=1.66$; $t=3.67, p<0.001)$. An ANOVA with risk perceptions as the dependent variable indicated that low AC scenario resulted in lower risk perceptions $(M=3.82, \mathrm{SD}=1.40)$ than the high AC scenario $(M=5.40, \mathrm{SD}=0.89$; $F(1,63)=27.11, p<0.001)$.

A second pre-test for the purity scenario was run using a sample of sixty-three U.S. citizens (70\% female; $M_{\text {age }}=43$ years) on Mturk. The study manipulated AC on two levels (low vs. high), identical to the previously created scenarios. After random assignment to one of the AC levels, participants responded to the same items in the prior pre-test. Unfortunately, risk perceptions did not differ among scenarios $(F<1)$. Thus, the AC strength from the scenario was enhanced to strengthen the manipulation of high AC (included in "Appendix A: Moral Violation Scenarios"), and additional data were collected, resulting in an Mturk sample of 64 U.S. citizens (60\% female; $M_{\text {age }}=41$ years $)$. This time, there was a significant difference between the low $\mathrm{AC}(M=5.20, \mathrm{SD}=1.57)$ and high $\mathrm{AC}(M=6.00, \mathrm{SD}=0.90 ; F(1,63)=6.62, p<0.001)$ scenarios on risk perceptions. As expected, no differences emerged when examining morality $(F<1 ; \alpha=0.94)$ or purity scenarios $(F<1)$ as dependent variables. A single $t$ test (test value $=4$ ) indicated that participants perceived the purity scenarios reflective of immorality $(M=3.42$, $\mathrm{SD}=1.39 ; t=-3.32, p<0.01)$ and purity $(M=4.81$, $\mathrm{SD}=1.82 ; t=4.00, p<0.001)$. Therefore, the scenarios were deemed relevant for the population.

\section{Study 1: Purity Moral Violation}

The goal of this study was twofold. First, we aimed to respond to the first research question, whether both regulatory focus and AC affect brand evaluations. We expect that individuals with a prevention mindset will judge a brand less negatively if AC is low (vs. high). The low and improved high AC scenarios from the third pre-test were employed for this study. Second, the study tests an alternative explanation to moral decoupling account, individual political orientation.

\section{Participants, Procedure, and Stimuli}

One hundred and forty-one U.S. citizens (53\% male; $M_{\mathrm{age}}=36$ years) participated in an online Mturk study. The study consisted of two manipulated factors with two levels each in a between subjects design: regulatory focus (prevention vs. promotion mindset) and AC (low vs. high).

We informed participants that they would be taking part in two separate studies. First, they completed a writing task to manipulate regulatory focus orientation. Following Higgins et al. (2003), each participant wrote an essay focused on his/her current hopes and aspirations and future accomplishments (i.e., promotion prime) or his/her current duties and obligations and responsibilities (i.e., prevention prime) compared to childhood. Next, participants were randomly assigned to a political scenario, which varied by AC (low vs. high), where a candidate sought election (see "Appendix A: Moral Violation Scenarios" for scenarios).

Next, participants evaluated the brand (i.e., candidate) operationalized by voting intentions for the candidate. Voting intentions served as a viable measure of brand evaluation for several reasons. First, voters evaluate and allocate their support for politicians in the same manner that consumers do towards brands and social groups (Bennett et al. 2019). Second, voting intentions capture the conative (i.e., behavioral) dimension of consumers' attitude towards the brand (i.e., candidate), reflecting their assessment of the brand. Finally, this approach is in line with prior research (see Dekhili and Achabou 2015; Van den Broek et al. 2017). Five bipolar items were used ("Please rate how likely you are to vote for Charles Johnson" with options Never/Definitely; Probably not/Probably; Definitely against/Definitely for; Definitely do not intend to/Definitely intent to; Very low probability/Very high probability; $\alpha=0.98$; Spears and Singh 2004). Then, they evaluated whether they believed the politician was supported by a large political party $(1=$ not at all; $7=$ very much). This was considered a covariate given that the narrative did not indicate a political party (see Van Steenburg 2015) and the fact that support from a secondary brand can influence moral judgment. After reporting if they were registered to vote $(89.4 \%)$, participants indicated their political orientation through one item in line with Iyer 
et al. (2012): "Although it is often difficult to summarize one's political, economic, and social views in a single word or phrase, please indicate which of the following positions best represents your viewpoint" ( 1 = very liberal; 7 = very conservative) and were found to have moderate political views $(M=3.72, \mathrm{SD}=1.81)$. Next, participants responded to the regulatory focus manipulation check item, "Pursuing one's hopes and dreams at all costs are very important" ( $1=$ strongly disagree; $7=$ strongly agree), where higher (lower) scores indicate a promotion (prevention) mindset. Then, they answered two items designed to capture the manipulation effectiveness of AC using a 7-point bipolar scale (e.g., "How would you characterize the situation faced by Charles Johnson?- Potential for Gain/Potential for Loss; Positive Situation/Negative Situation;" $\alpha=0.70$ ). Higher scores indicated AC is felt more (e.g., high AC). Finally, participants provided demographic information before debriefing, where age and gender served as covariates since moral judgment develops over time (Walker 1989) and Gilligan (1982) suggests it is possible that genders differ in fundamental moral reasoning.

\section{Results}

Preliminary Analysis To check the regulatory focus manipulation, we ran an ANCOVA with regulatory focus prime $(0=$ prevention, $1=$ promotion $)$ and $\mathrm{AC}(0=$ low, $1=$ high $)$ as independent variables, age $(p=0.003)$, gender, and party support perceptions ( $p$ 's $>0.1$, dropped from further analysis) as covariates, and the regulatory focus manipulation check as the dependent variable. As expected, the ANOVA revealed only a main effect of the regulatory focus prime. Those in the promotion (vs. prevention) mindset were more inclined to pursue their hopes and dreams $(M=4.75, \mathrm{SD}=1.68$ vs. $M=4.29, \mathrm{SD}=1.54$, respectively; $F(1,140)=3.80 ; p=0.05)$. An identical ANCOVA (where age was the only significant $(p=.03)$ covariate) was run with the $\mathrm{AC}$ manipulation check as the dependent variable, revealing only a significant effect for the AC condition $(F(1,140)=3.87 ; p=0.05)$. Those assigned to the low AC condition perceived lower perceptions of consequences $(M=4.23, \mathrm{SD}=1.44)$ than those assigned the high AC condition $(M=4.74, \mathrm{SD}=1.30)$.

Brand Evaluations An ANCOVA with regulatory focus prime and $\mathrm{AC}$ as the independent variables, with age ( $p=0.003)$, gender, and party support perceptions ( $p$ 's $>0.1$, dropped from further analysis) as covariates and brand evaluations as the dependent variable provided a significant interaction supporting $\mathrm{H} 1$ as shown in Table 2 .

Planned contrasts revealed that in the prevention prime, low (vs. high) AC resulted in less-negative brand evaluations. However, for the promotion prime, AC had no impact, supporting $\mathrm{H} 1$. With low AC, the prevention (vs. promotion) prime led to less-negative brand evaluations. Though, for the high AC condition, there was no difference in brand evaluations. Figure 1 illustrates these relationships.

To rule out the alternative explanation that an individual's political orientation rather than regulatory focus orientation explains differences in brand evaluations, we considered political orientation as a covariate and ran another identical ANCOVA. The results were similar with and without the political orientation as a covariate (i.e., despite the significance of political orientation as a covariate $(F(1,140)=8.00$, $\left.p<0.01, \eta^{2}=0.06\right)$, the significance of the two-way interaction strengthened $\left(F(1,140)=5.62, p<0.02, \eta^{2}=0.04\right)$, and the planned contrasts remained intact).

\section{Discussion}

The results provide initial support for moral decoupling stemming from regulatory focus, while rejecting the alternative account based on individual political orientation. Specifically, political orientation did not change the interaction of AC and regulatory focus on brand evaluations. This study supports our theorizing, at least in a purity violation scenario, that individuals in a prevention mindset report less-negative brand evaluations when consequences to the brand was low (H1). Specifically, differences within the prevention prime at high versus low AC indicate that when individuals experience a prevention mindset, they are more capable of evaluating a brand separately from his/ her moral evaluation. However, when experiencing a promotion mindset, individuals do not process different pieces of information independently and form evaluations in a holistic manner. Still, more research is needed to generalize these results across other moral violations. Therefore, we devised a second study to add greater generalizability.

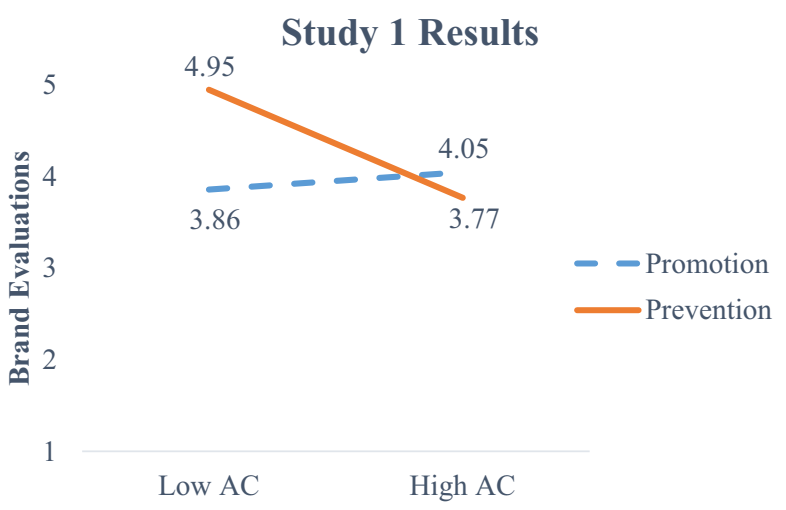

Fig. 1 Interaction of regulatory focus $\times \mathrm{AC}$ on brand evaluations for purity violations 


\section{Study 2: Authority Moral Violation}

The goal of this study was threefold. First, we aimed to provide additional support that a prevention mindset can facilitate decoupling. Second, we sought to increase generalizability by examining a new context (i.e., authority) that is job-related for politicians. More specifically and in the context of politics, brand performance depends on leadership qualities (Guzmán and Sierra 2009), which are built over time. As such, political brand judgments are based on whether they respect established codes of conduct (Bertolotti et al. 2013; Laurent et al. 2014; Tweneboah-Koduah et al. 2010), consistent with respect of authority. Moreover, prior research on voters' perceptions of politicians has highlighted the importance of brand authority in successful candidates (Needham and Smith 2015). Thus, we chose to employ the authority moral scenario. Second, we changed the regulatory focus prime from a writing task to viewing a political ad to increase the ecological validity of the study. We expect that individuals with a prevention mindset will judge a brand less negatively if $\mathrm{AC}$ is low versus high. Finally, the study tested individual political orientation as an alternative explanation.

\section{Participants, Procedure, and Stimuli}

One hundred thirty-five U.S. citizens (58\% female; $M_{\text {age }}=38$ years) participated in an online Mturk study. The study consisted of two manipulated factors on two levels each in a between subjects design: regulatory focus prime (prevention vs. promotion mindset) and AC (low vs. high).

Participants were randomly assigned to a prevention or promotion regulatory focus prime. Specifically, participants viewed a video advertisement for a political brand. The design, layout, and sounds were identical across conditions, with the exception of the wording in the ad, similar to Mogilner et al. (2008). Keywords in the videos differed according to prevention versus promotion priming. For instance, the promotion (prevention) video referred to voting as an opportunity (responsibility) and described the hypothetical candidate as an ideal candidate (a candidate you need) that the American people can be proud of (won't regret). The full ad played for $65 \mathrm{~s}$ (see "Appendix B: Promotion and Prevention Priming"). The political brand appeared as a neutral party individual running for political office in the United States.

After viewing the advertisement, participants read one of two AC scenarios reflecting authority, developed from the pre-tests. Next, participants responded to the brand evaluation measures operationalized as intent to vote as in Study $1(\alpha=0.99$; Spears and Singh 2004). As a manipulation check, participants also indicated the degree to which the ad reflected a promotion (vs. prevention) mindset using four items (e.g., "Which of the following phrases best describes Charles Johnson as a candidate?" where $1=i d e a l / a n$ opportune choice/something positive/pursuing a good choice and $7=$ necessary/a secure choice/something negative/avoiding a bad choice; $\alpha=0.79$; Mogilner et al. 2008). Higher scores indicated prevention mindset. Next, individuals completed the same AC perception item as in study 1 , with higher scores signaling high AC. Before completing demographics, participants indicated whether they believed the politician was supported by a large political party $(1=$ not at all; $7=$ very much).

\section{Results}

Preliminary Analysis To check the regulatory focus manipulation, we conducted an ANCOVA with the regulatory focus prime $(0=$ prevention, $1=$ promotion $)$ and $\mathrm{AC}(0=$ low, $1=$ high) as independent variables, with age, gender, and party support perceptions as covariates (all $p$ 's $>0.1$ ), and the manipulation check items as the dependent variable. As expected, ANOVA revealed only a main effect of regulatory focus, where those in the promotion (vs. prevention) prime were less likely to think of the political brand with a prevention mindset $(M=4.89, \mathrm{SD}=1.74$ vs. $\mathrm{M}=3.12, \mathrm{SD}=1.64$ prevention vs. promotion; $F(1,135)=37.83 ; p=0.001$ ). Next, the same ANCOVA was run with the AC perceptions as the dependent variable. Aside from party support as a significant covariate $(p<0.001)$, only a significant effect was revealed for the AC manipulation $(F(1,135)=5.92$, $p<0.02)$. Those in the high AC condition reported more consequences $(M=4.96, \mathrm{SD}=1.49)$ versus those in the low AC condition $(M=4.18, \mathrm{SD}=1.68)$.

Brand Evaluations An ANCOVA with regulatory focus and $\mathrm{AC}$ as independent variables; age $(p=0.03)$, gender ( $p>0.1$, dropped from further analysis), and party support $(p<0.001)$ as covariates; and brand evaluation as the dependent variable provided a significant interaction, supporting H1, as shown in Table 2 .

Planned contrasts within the promotion prime revealed no differences in brand evaluations between the AC conditions. However, as expected, those primed with a prevention mindset reported less-negative brand evaluations with low (vs. high) AC, consistent with $\mathrm{H} 2$. Moreover, planned contrasts within the high AC condition showed that evaluations were worse for those primed with a prevention (vs. promotion) mindset. Within low AC, regulatory focus did not influence evaluations, as shown in Fig. 2.

To rule out the alternative explanation that an individual's political orientation rather than regulatory focus orientation explains differences in brand evaluations, we considered political orientation as a covariate and ran an additional ANCOVA. While political orientation was not significant $(p>0.58)$, the two-way interaction remained significant $\left(F(1,137)=3.77, p<0.05, \eta^{2}=0.03\right)$, lending support to 


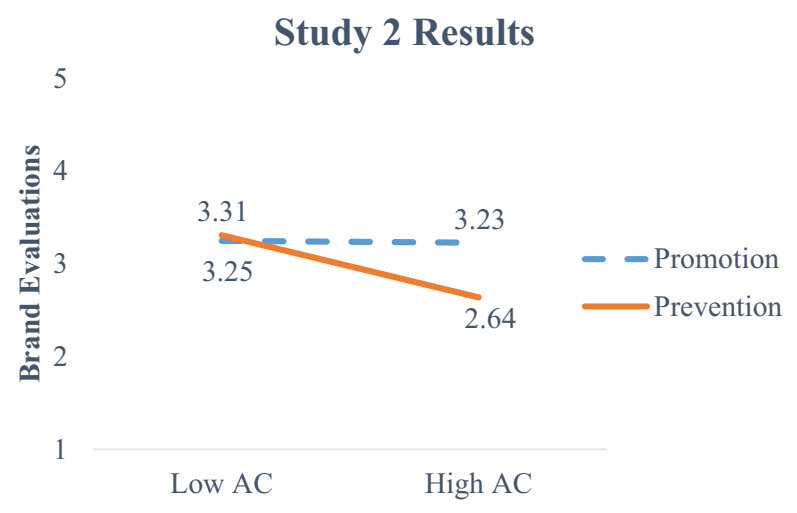

Fig. 2 Interaction of regulatory focus $\times$ risk mitigation on brand evaluations for authority violation

our argument that political orientation does not explain the results.

\section{Discussion}

The results provide further support for the role of regulatory focus orientation as a motivational driver of decoupling. Similar to study 1 , which focused on purity (i.e., unrelated to political job performance), study 2 indicates that those in a prevention mindset can engage in moral decoupling, evaluating the brand differently based on AC. Study 2 (in comparison with study 1) sheds new light on prevention mindset by demonstrating that those in a prevention mindset evaluate the brand more harshly than those in a promotion mindset in case of a moral violation related to political job performance (i.e., authority violation). Still, those in a promotion mindset consistently evaluate the brand. Study 2 shares a novel finding for regulatory focus literature by showing an instance where individuals in a prevention mindset may be less capable of decoupling (dissociating moral information from performance in their evaluations). We argue this inability results in experiencing internal tensions (negative emotions) that will impact evaluations. Moral violation type and the relatedness of the violation to the brand's performance may provide a boundary condition to what we traditionally understand about prevention regulatory focus orientation. To explore this more and examine whether emotions indeed explain these processes, we devised a third study.

\section{Study 3: Moral Foundation Violations (Un)Related to Job Performance}

The objectives of Study 3 were twofold. First, we replicated the moral violation contexts controlling for $\mathrm{AC}$ in order to increase the confidence in the study results and further support theorizing. We expect authority violations to result in greater damage to political brands due to their relevance to politicians' job performance (see Walzer 1978, 1980). However, purity violations do not impede, improve, or affect job performance for a politician and are considered to be less relevant to job performance in politics. Thus, such violations are expected to be less damaging to the brand and more likely to be judged by consumers following moral decoupling strategies (depending on consumers' regulatory focus). As these types of violations represent moral foundations related (vs. not related) to the brand's job performance, we examine this in Study 3. Second, we aimed to examine the dynamics of moral decoupling strategies within the prevention mindset via testing an underlying mechanism, negative emotions.

\section{Participants, Procedure, and Stimuli}

One hundred fifty-three U.S. citizens ( $54 \%$ female; $M_{\text {age }}=38$ years) participated in an online study on Mturk. The design of the study consisted of two manipulated factors on two levels in a between subjects design: regulatory focus prime (prevention vs. promotion mindset) and high AC scenario (purity vs. authority).

Participants were randomly assigned to a regulatory focus prime (prevention vs. promotion), identical to study 2. After viewing the advertisement, participants read the high AC versions of one of two moral foundation scenarios (see Appendix A). Next, they completed the brand evaluation measure $(\alpha=0.99)$. However, to examine hypothesis 4 , participants also rated the extent to which they felt negative emotions (5 items: anger, disgust, sadness, anxiety, and disappointment) on a 7-point scale (where $1=$ not at all and $7=$ extremely; $\alpha=0.89$ ) followed by the same party support perceptions. Then, they responded to the same manipulation check items for the regulatory focus prime $(\alpha=0.86)$. In order to check the extent to which the scenarios differed on job performance, participants responded to one item ("Thinking back to the scenario you read, indicate the extent to which the scenario concerns something related to his job" $1=$ not at all, $7=$ very much). Lastly, participants completed demographic items, indicating that $95 \%$ were registered to vote.

\section{Results}

Preliminary Analysis To check the regulatory focus orientation manipulation, we ran an ANCOVA with the regulatory focus prime $(0=$ prevention, $1=$ promotion $)$, moral violation $(0=$ purity, $1=$ authority $)$, and their interactions as independent variables, with age and party support as covariates, and the manipulation check items as the regulatory focus manipulation check as the dependent variable. The ANCOVA with age $(p<0.001)$ and party support $(p<0.02)$ 
as covariates revealed only a significant main effect of the regulatory focus prime, in that those in the promotion (vs. prevention) mindset were less likely to think of the political brand with a prevention focus $(M=5.25, \mathrm{SD}=1.27$ vs. $M=2.48, \mathrm{SD}=0.94$, for prevention vs. promotions; $F(1,152)=248.42 ; p=0.001)$. An identical ANCOVA, with age $(p<.01)$ and party support $(p<0.001)$ as significant covariates, was run with relatedness to job performance as the dependent variable, revealing only a significant main effect for the situation type $(F(1,152)=58.58, p<0.001)$. Those assigned the authority condition reported the situation as more job-related $(M=4.35, \mathrm{SD}=1.67)$ than those assigned the purity scenario $(M=2.22, \mathrm{SD}=1.74)$.

Brand Evaluations An ANOVA with regulatory focus prime, moral scenario, and their interaction as the independent variables, with age $(p<0.01)$, gender $(p>0.1$, dropped from further analysis), and party support $(p<0.001)$ as covariates, and brand evaluations as the dependent variable, revealed a significant main effect of moral situational context (purity vs. authority), indicating that the authority violation was evaluated more negatively compared to the purity violation (supporting H2). More importantly, as hypothesized, there was a significant interaction between moral violation scenario and regulatory focus, as shown in Table 3. Additional analysis was conducted including political orientation as a covariate to demonstrate the robustness of our findings. While political orientation was not significant $(p>0.13)$, the two-way interaction remained significant $(F(1,152)=3.74$, $p=0.05, \eta^{2}=0.03$ ), lending support that political orientation does not explain our results.

Planned contrasts revealed within the promotion mindset reported no differences in brand evaluations for the purity versus authority scenario. As predicted, those primed with a prevention mindset reported less-negative brand evaluations for the purity scenario than for the authority scenario. In the purity scenario, brand evaluations were less negative for those primed with a prevention versus promotion mindset. Those who read the authority scenario reported similar brand evaluations across both regulatory focus priming conditions, as shown in Fig. 3, lending support to H3.

Negative Emotions To explore the role of negative emotions as the underlying mechanism for the interaction between regulatory focus orientation and moral violation type on brand evaluations, a moderated mediation analysis using PROCESS Model 8 (Hayes 2012) was conducted. In the regression model, brand evaluation was the dependent variable, moral scenario, regulatory focus prime, and their interaction term served as predictors and negative emotions was the mediator.

A bootstrap analysis supports the $\mathrm{H} 3$ and $\mathrm{H} 4$ account of mediated moderation, showing that the indirect effect of the
Study 3 Results

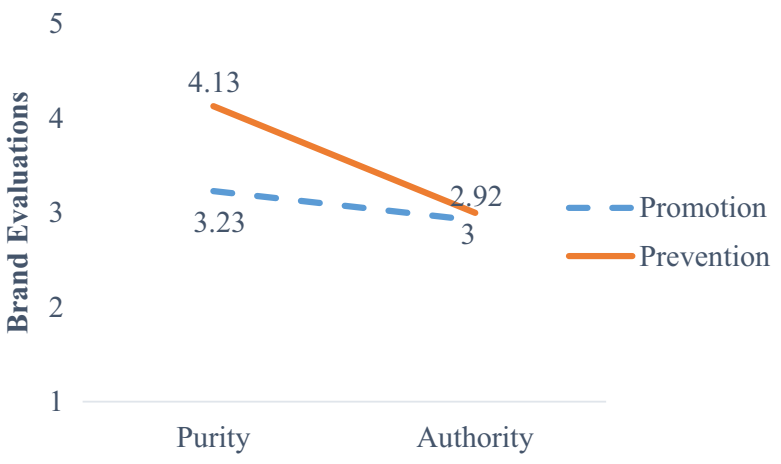

Fig. 3 Interaction of regulatory focus $\times$ moral violation type on brand evaluations

highest order interaction was significant $($ Index $=-0.21$; 95\% CI LL $=-0.4647$; UL $=-0.0154$ ). Additionally, the effect of the moral scenario and regulatory focus prime interaction on negative emotions was significant $(\beta=1.05$; $t=2.45 ; p<0.02)$, as was the effect of negative emotions on brand evaluations $(\beta=-0.20 ; t=-2.60 ; p=0.01)$. Specifically, the indirect effect through the mediator provided evidence that within a prevention mindset, emotions led to more negative evaluations in an authority (vs. purity) scenario $(\beta=-0.14 ; 95 \% \mathrm{CI} L L=-0.3223$; $\mathrm{UL}=-0.0037)$. Yet, no differences in emotions occurred across moral scenarios for individuals with a promotion mindset $(\beta=0.07$; 95\% CI LL $=-0.0408$; $\mathrm{UL}=0.2134$ ).

\section{Discussion}

The results offer further evidence that brand evaluations differ by regulatory focus, consistent with the ability to separate judgments of the brand and judgments of immorality. Moreover, relatedness to job performance serves as a boundary condition. The findings show that a promotion mindset is less conducive to moral decoupling and thus is expected to influence brand evaluations following a moral violation regardless of the type of violation and its relatedness to a brand's job performance. However, a prevention mindset is more conducive to employing moral decoupling (which avoids compromising the self-concept). When the moral foundation violation is not directly related to the brand's performance (i.e., purity violation for a political brand), decoupling is facilitated, and less-negative emotions occur. Conversely, when the moral violation is related to a brand's performance, it is difficult to attenuate negative evaluations, and thus those in a prevention mindset experience negative emotions. As such, the results offer further support for decoupling, while identifying a boundary condition (relatedness) and an underlying mechanism (negative emotions) 
Table 1 ANCOVA results of study 1
Table 2 ANCOVA results of study 2

\begin{tabular}{llllll}
\hline Dependent variable: brand evaluations & $F(1,140)$ & $p$ value & $\eta^{2}$ & $M_{0}(\mathrm{SD})$ & $M_{1}(\mathrm{SD})$ \\
\hline Regulatory focus prime (RFP) & 1.65 & $\mathrm{~ns}$ & 0.01 & $4.36(1.85)$ & $3.97(1.74)$ \\
Awareness of consequences (AC) & 2.21 & $\mathrm{~ns}$ & 0.02 & $4.36(1.80)$ & $3.95(1.77)$ \\
RFP $\times$ AC & 4.76 & 0.03 & 0.03 & & \\
Planned contrasts & & & & & \\
Prevention (0) & 6.94 & 0.01 & 0.09 & $4.95(1.79)$ & $3.77(1.75)$ \\
Promotion (1) & 0.25 & $\mathrm{~ns}$ & $<0.01$ & $3.86(1.69)$ & $4.05(1.79)$ \\
AC low (0) & 6.39 & 0.01 & 0.09 & $4.95(1.79)$ & $3.86(1.69)$ \\
AC high (1) & 0.49 & $\mathrm{~ns}$ & $<0.01$ & $3.77(1.75)$ & $4.05(1.79)$ \\
\hline
\end{tabular}

$\operatorname{RFP}(0=$ prevention, $1=$ promotion $)$

$\mathrm{AC}(0=$ low, $1=$ high $)$

\begin{tabular}{lllrll}
\hline Dependent variable: brand evaluations & $F(1,137)$ & $p$ value & \multicolumn{1}{c}{$\eta^{2}$} & \multicolumn{1}{l}{$M_{0}(\mathrm{SD})$} & \multicolumn{1}{c}{$M_{1}(\mathrm{SD})$} \\
\hline Regulatory focus prime (RFP) & 1.24 & $\mathrm{~ns}$ & 0.01 & $2.96(1.69)$ & $3.24(1.72)$ \\
Awareness of consequences (AC) & 0.00 & $\mathrm{~ns}$ & $<0.01$ & $3.29(1.79)$ & $2.93(1.62)$ \\
RFP $\times$ AC & 4.16 & 0.04 & 0.03 & & \\
Planned contrasts & & & & & \\
Prevention (0) & 5.06 & 0.02 & 0.04 & $3.31(1.78)$ & $2.64(1.56)$ \\
Promotion (1) & 0.00 & $\mathrm{~ns}$ & $<0.01$ & $3.25(1.84)$ & $3.23(1.65)$ \\
AC low (0) & 0.04 & $\mathrm{~ns}$ & $<0.01$ & $3.31(1.78)$ & $3.25(1.84)$ \\
AC high (1) & 4.04 & 0.04 & 0.03 & $2.64(1.56)$ & $3.23(1.65)$ \\
\hline
\end{tabular}

$\operatorname{RFP}(0=$ prevention, $1=$ promotion $)$

AC $(0=$ low, $1=$ high $)$

Table 3 ANCOVA results of study 3

\begin{tabular}{lcllll}
\hline Dependent variable: brand evaluations & $F(1,152)$ & $p$ value & $\eta^{2}$ & $M_{0}(\mathrm{SD})$ & $M_{1}(\mathrm{SD})$ \\
\hline Regulatory focus prime (RFP) & 1.85 & $\mathrm{~ns}$ & 0.01 & $3.08(1.40)$ & $2.71(1.61)$ \\
Moral situational context (MSC) & 20.11 & 0.001 & 0.12 & $3.07(1.61)$ & $2.08(1.39)$ \\
RFP×MSC & 3.93 & 0.05 & 0.03 & & \\
Planned contrasts & & & & & \\
Prevention (0) & 15.59 & 0.001 & 0.22 & $4.13(1.32)$ & $3.00(1.40)$ \\
Promotion (1) & 1.16 & $\mathrm{~ns}$ & 0.04 & $3.23(1.46)$ & $2.92(1.33)$ \\
Purity (0) & 9.78 & 0.001 & 0.07 & $4.13(1.32)$ & $3.23(1.46)$ \\
Authority (1) & 0.08 & $\mathrm{~ns}$ & $<0.01$ & $3.00(1.40)$ & $2.92(1.33)$ \\
\hline
\end{tabular}

RFP $(0=$ prevention, $1=$ promotion $)$

$\mathrm{AC}(0=$ purity [unrelated], $1=$ authority [related] $)$ for when and how such strategies are experienced. These insights add specificity regarding the role of regulatory focus in decoupling strategies.

The results of study 3 confirm the overall thesis of the present research regarding the role of regulatory orientation in judgment of different moral violations. However, it is noteworthy that comparing planned contrasts within the regulatory mindsets for authority and purity violations (despite not being the focal contrasts hypothesized) shows slightly different results from studies 1 and 2 (please refer to Tables 1,2, and 3). We believe these differences could have arisen for several reasons. First, the priming of regulatory focus orientation was strengthened for studies 2 and 3 , potentially resulting in more stringent reflections of each mindset versus that used in study 1 . As such, a significant difference may have emerged within the purity scenario between the promotion and prevention mindset, where the difference was non-significant in study 1 . Second, other potential moderators could explain some of these changes. Although within the authority scenario, the results are directionally similar, the differences are not significant in study 3 . One explanation could be the participants' own prior moral 
behavior, which moderates the influence of regulatory focus on consumers' moral behavior (Schwabe et al. 2018). Additionally, perceptions of behavioral integrity, the perceived alignment between an individual's words and deeds (Simons 2002; Palanski et al. 2011), could have influenced the impact of regulatory focus on consumer responses. Specifically, in a prevention mindset, individuals' responses and behaviors are strengthened (Kacmar and Tucker 2014). As aforementioned, while not the focus of this third study, differences did emerge. This provides several directions for future research to explore in depth.

\section{General Discussion}

The results of three experiments support the hypothesized relationships between moral violation type, AC of moral violations, regulatory focus, and brand evaluations. Though we used a political context to explore these relationships, it is expected that the results are generalizable to business and brand situations. Specifically, the studies respond to the question regarding how some brands experience positive evaluations following a moral violation while others do not, by providing insights on who, when, and how decoupling strategies are employed as a means to attenuate negative judgment towards violating businesses and brands. Further, the results help reject an alternative account that an individual's political orientation explains moral decoupling tendencies.

Studies 1 and 2 provide support that individuals with a prevention mindset evaluate a brand that has violated a moral foundation less negatively when AC is low (vs. high). This pattern of results occurs for violations unrelated to brand performance (study 1; purity violation) and related to performance (study 2; authority violation). Moreover, when AC is low and the violation is not performance-related, those with a prevention mindset evaluate the brand less negatively than those with a promotion mindset, supporting moral decoupling (study 1). However, in high AC scenarios, moral violations related (vs. unrelated) to the brand's performance are more damaging (study 3 ), and cause difficulty in employing moral decoupling even by prevention-oriented individuals, resulting in negative emotions. The underlying mechanism, negative emotions, further explains our theorizing for why consumers negatively evaluate businesses and brands. This work provides several theoretical and practical contributions.

\section{Theoretical and Managerial Contributions}

First, while recent work has contributed to our understanding of moral rationalization and decoupling strategies, a gap remains as to when individuals might employ a moral decoupling strategy and which individuals are more likely to employ such strategies. The present research addresses these gaps. We specifically chose a context (e.g., political branding) where moral decoupling strategies may be harder to engage in, as performance is more subjective (e.g., Bhattacharjee et al. 2012) in order to delineate how decoupling strategies are employed. Past research has identified certain conditions prompting moral decoupling, including high brand identification (Lee et al. 2015) and when the moral violation is not related to job performance (Lee and Kwak 2016). Our research contributes to this literature, by supporting regulatory focus as a motivational drive state explaining why some individuals might be more prone to decoupling. In line with prior research demonstrating that moral decoupling strategies prevent consumers from experiencing negative emotions (Lee et al. 2016) and that job-related moral violations hinder moral decoupling strategies (Lee and Kwak 2016), our research provides parallel evidence for individuals with a prevention mindset. Specifically, those in a prevention mindset only exhibit more negative brand evaluations when they perceive high consequences and when the brand violates a performance-related norm. This is explained through negative emotions.

Second, past research suggests that having a prevention mindset motivates preventing losses by being analytical and risk-averse, while a promotion mindset involves pursuing gains by referencing feelings and hopes (Higgins 1997, 1998). These facts insinuate that someone with a promotion mindset would use feelings to judge a brand following a moral violation, whereas someone with a prevention mindset would use facts and assessment of consequences to evaluate this brand. Supported by distinct information processing styles of promotion and prevention mindsets, we provide evidence across three studies that regulatory focus orientation can motivate or hinder decoupling strategies. Moreover, we document that those in a prevention mindset can experience more negative emotions in their judgments when the brand violates a moral foundation related to its job activities. This research provides one instance where having a prevention mindset may stir negative emotions, which may cause these individuals to more harshly evaluate brands (vs. those in a promotion mindset).

Third, this research acknowledges conflicting accounts for moral judgments. While some research, based on the NAM, suggests that individuals use logic to judge moral misdeeds based on AR, AC, and PN (Schwartz and Howard 1981), others claim that emotions are more likely to guide judgment and decision-making (Haidt 2001). The former is consistent with a moral decoupling process that disentangles the moral violation from personal judgment of a brand. The NAM specifies that highly felt personal norms and high culpability for immoral actions lead to harsher judgments following immorality (Bloom 2013; De Groot and Steg 2009; DeSteno et al. 2004; Haidt 2001; Newman 2003). Yet, the latter posits 
that emotions cause the evaluations of the person or brand to be equivalent to evaluations of the moral violation. This research suggests that the NAM model, compatible with literature on moral decoupling, is a strategy employed by those with a prevention mindset, unless the violation is job-related. On the other hand, those in a promotion mindset follow the emotional route to evaluations, consistent with the account led by researchers such as Haidt (2001) and colleagues. Thus, this research bridges these literatures.

Lastly, this research enhances the business ethics literature by drawing on regulatory focus theory, moral foundations theory, and the NAM to bring new perspectives to understanding the dynamics of brand evaluations in the midst of moral violations. The proliferation of corporate, social, and political scandals has pushed researchers to assess these scandals to understand and predict consumers' reactions to transgressions (Sturm 2017). This research specifically uses a political brand context given the extensive media coverage and public attention to politicians' moral transgressions. Our research provides one instance generalizing moral decoupling to these more subjective areas. The findings suggest that moral violations can be deemed less harmful to businesses and brands if they do not violate moral foundations related to on-the-job-performance as long as the brand can avoid negative consequences and facilitate a prevention mindset in consumers. Our research evinces that advertising can motivate a prevention mindset, though other research speaks to priming a prevention mindset by other means (e.g., press releases, language). This also helps political brands and addresses gaps in political research (Guzmán et al. 2014; Guzmán and Sierra 2009) by investigating political brand evaluations (Van Steenburg 2015).

\section{Future Research and Limitations}

In order to examine moral violations, we controlled for cross-country political biases by using a U.S population. Still, further research should explore whether the findings are generalizable in other Western contexts and cultures with greater cultural differences. Moreover, we did not take into account an individual's level of involvement with the violation (e.g., authority subversion and purity), which potentially limits the results of the study. We did, however, measure indirect indicators of issue involvement (e.g., religiosity, political involvement, political cynicism, and skepticism) and found no significant effects. While past research documents brand involvement as a moderator (e.g., Lee et al. 2015), it could be that issue involvement also moderates the motivation an individual has to employ moral decoupling, such that lower (greater) issue involvement might be more (less) amenable to moral decoupling. More research is needed to explore these tendencies in greater detail.
Although party support was included as a covariate across studies, it was not the scope of this research to investigate how support from another brand could alleviate emotional judgment, leading to a moral decoupling strategy. Yet, perhaps this is the case. The positive role of party support hints to a positive endorsement effect. Nike used Tiger Woods and Charles Barkley in its advertising. Could this be one reason why Tiger Woods was not negatively judged, aside from the fact that his violation was non-jobperformance-related? This would be a fruitful avenue for future business ethics research.

Additionally, future research should investigate instances where a prevention mindset leads to greater or less use of emotion in decision-making. For this research, we chose authority and purity violations, as they are clearly related (and unrelated) to the brand's job performance in our study context. Yet, we chose types of violations (e.g., open marriage and data collection) that some people might deem acceptable. Thus, future research should be undertaken to investigate whether clear violations (e.g., extramarital affair) would reproduce the results or prevent decoupling. Further, as indicated by the discussion after study 3 , there were some discrepancies in non-hypothesized relationships. While we argued that this could be due to different priming methods and additional moderators, more research is needed. In particular, participants' own prior moral behavior may influence the relationship between regulatory focus and consumers' evaluations following varying moral violations (Schwabe et al. 2018). Moreover, we suggest assessing the role of behavioral integrity, the perceived alignment between an individual's words and deeds (e.g., Kacmar and Tucker 2014; Palanski et al. 2011; Simons 2002), in moderating how those in a prevention mindset evaluate moral violations. Finally, future research should test how different foundations impact the extent of judgment in other subjective contexts, such as business leadership in cross-cultural settings.

\section{Compliance with Ethical Standards}

Conflict of interest All authors declare that they have no conflict of interest.

Ethical Approval This article does not contain any studies with animals performed by any of the authors. All procedures performed in studies involving human participants were in accordance with the ethical standards of the institutional and/or national research committee and with the 1964 Helsinki Declaration and its later amendments or comparable ethical standards.

Informed Consent Informed consent was obtained from all individual participants included in the study. 
Open Access This article is distributed under the terms of the Creative Commons Attribution 4.0 International License (http://creativeco mmons.org/licenses/by/4.0/), which permits unrestricted use, distribution, and reproduction in any medium, provided you give appropriate credit to the original author(s) and the source, provide a link to the Creative Commons license, and indicate if changes were made.

\section{Appendix A: Moral Violation Scenarios}

\section{All Scenarios Included the Following Text}

Charles Johnson is currently involved in U.S. politics. He has a wife named Lisa and is currently running for president. Charles Johnson has two priorities in his campaign: (1) the state of the economy and (2) health care affordability.

\section{Authority Violation Scenario}

During Charles Johnson's membership of the Presidential Cabinet, he created a new method for collecting security information. Charles Johnson did not seek permission from the current President or administrative staff first, because there was no policy explicitly forbidding it. There is already an information system in place that he could use, which serves the same purpose. Charles Johnson thought that it would be easier for him to use a secondary system. He remains in full control of the secondary system, refusing to hand over to anyone else.

Low $A C$ When the President and administration discovered harles' actions, they were not mad. Charles felt no regrets about his actions and did not suffer any negative consequences. His actions did not cause any negative consequences for anyone else.

High AC The President and administration discovered Charles Johnson's actions. Charles Johnson felt no regrets about his actions but wonders what would happen to his career.

\section{Purity Violation Scenario}

During Charles Johnson's membership of the Presidential Cabinet, he and his wife Lisa engaged in extramarital affairs, because Charles Johnson and Lisa have unconventional attitudes to marriage; they have agreed to an open marriage. As a result, they often solicited sexual partners outside their marriage.

Low AC Lisa takes birth control pills, Charles always uses a condom, and their partners are always similarly cautious. When Charles Johnson decided to run for nomination as president, they decided to give up their alternative lifestyle.
They feel no regrets about their past and have experienced no negative consequences. Likewise, none of their past partners regret their involvement or have experienced negative consequences.

High AC (from professional pre-test only) When Charles received his party's nomination for congress, they decided to give up their alternative life style.

High AC (used in third pre-test and studies 1 and 3) Lisa does not take birth control pills and Charles does not use a condom. When Charles received his party's nomination for congress, they decided to give up their alternative life style.

\section{Appendix B: Promotion and Prevention Priming}

Participants were asked to watch a political ad for the candidate created using adobe spark. These ads began "Over the next 4 months you have a decision to make."

The text for the promotion (prevention) ad reads:

Slide 1 with white house image: Over the next 2 months you will have a choice to make.

Slide 2 with a gray image of the world in a hand: Your decision matters for America.

Slide 3 blank It's an opportunity (a responsibility) we all share.

Slide 4 with rows of tiny American flags in the ground: Charles Johnson is an ideal candidate (a candidate you need) - the one America can be proud of (won't regret).

Slide 5 blank: Why is he the optimal choice? (How can you be sure?)

Slide 6 with coins, pens, and pencils on a typed sheet of paper to the left of the text: With (Without) Charles Johnson, America will achieve (risks) economic prosperity (uncertainty).

Slide 7 shows an American flag with blurred people putting their hands on their hearts: America has much to hope for over (can't afford to gamble on) the next 4 years.

Slide 8 shows hands of persons in business attire shaking hands. The hands are painted the colors of the American flag: For America, the best choice is (needs) Charles Johnson.

Slide 9 shows a shadowed image of a speaker at a podium with supporters carrying posters: With (Without) Charles Johnson, cutting edge, affordable medical care is possible (medical coverage will decline while costs continue to rise). Slide 10 blank Give yourself a brighter (Don't settle for an uncertain) future.

Slide 11 only has an image of a "return" key patriotically painted with the word VOTE.

Slide 12 blank Charles Johnson for president. 


\section{References}

Anderson, C. (2003). The psychology of doing nothing: Forms of decision avoidance result from reason and emotion. Psychological Bulletin, 129, 139-167.

Bandura, A. (1999). Moral disengagement in the perpetration of inhumanities. Personality and Social Psychology Review, 3(3), 193-209.

Bennett, A. M., Malone, C., Cheatham, K., \& Saligram, N. (2019). The impact of perceptions of politician brand warmth and competence on voting intentions. Journal of Product \& Brand Management, 28(2), 256-273.

Bertolotti, M., Catellani, P., Douglas, K., \& Sutton, R. M. (2013). The 'big two' in political communication: The effects of attacking and defending politicians' leadership and morality in two European countries. Social Psychology, 44(2), 117-128.

Bhattacharjee, A., Berman, J. Z., \& Reed, A. (2012). Tip of the hat, wag of the finger: How moral decoupling enables consumers to admire and admonish. Journal of Consumer Research, 39(6), $1167-1184$

Bhattacharya, C. B., \& Elsbach, K. D. (2002). Us versus them: The roles of organizational identification and disidentification in social marketing initiatives. Journal of Public Policy and Marketing, 21(1), 26-36.

Bless, H., Mackie, D., \& Schwarz, N. (1992). Mood effects on attitude judgments: Independent effects on mood before and after message elaboration. Journal of Personality and Social Psychology, 63(4), 585-595.

Bless, H., Schwarz, N., Clore, G. L., Golisano, V., Rabe, C., \& Wolk, M. (1996). Mood and the use of scripts: Does a happy mood really lead to mindlessness? Journal of Personality and Social Psychology, 71(4), 665-679.

Bloom, P. B.-N. (2013). Disgust, harm, and morality in politics. Political Psychology, 35(4), 495-513.

Cannon, P. R., Schnall, S., \& White, M. (2011). Transgressions and expressions: Affective facial muscle activity predicts moral judgments. Social psychological and personality science, 2(3), 325-331.

Carver, C. S., \& Scheier, M. F. (1998). On self-regulation of behavior. New York: Cambridge University Press.

Chan, C., Van Boven, L., Andrade, E. B., \& Ariely, D. (2014). Moral violations reduce oral consumption. Journal of Consumer Psychology, 24(3), 381-386.

Crowe, E., \& Higgins, E. T. (1997). Regulatory focus and strategic inclinations: Promotion and prevention decision-making. Organizational Behavior and Human Decision Processes, 69(2), 117-132.

De George, R. T. (1987). The status of business ethics: Past and future. Journal of Business Ethics, 6(3), 201-211.

De Groot, J., \& Steg, L. (2009). Morality and prosocial behavior: The role of awareness, responsibility, and norms in the norm activation model. The Journal of Social Psychology, 149(4), 425-449.

Dekhili, S., \& Achabou, M. A. (2015). The influence of the countryof-origin ecological image on ecolabelled product evaluation: An experimental approach to the case of the European ecolabel. Journal of Business Ethics, 131(1), 89-106.

DeSteno, D., Petty, R. E., Rucker, D. D., Wegener, D. T., \& Braverman, J. (2004). Discrete emotions and persuasion: The role of emotion-induced expectancies. Journal of Personality and Social Psychology, 86(1), 43-56.

Diermeier, D. (2012, December 19). Top ten reputational crises-The 2012 edition. Accessed 11 November, from, 2016 http://reprules. wordpress.com/2012/12/19/top-tenreputational-crises-the-2012edition/.
Effron, D., Lucas, B. J., \& O’Connor, K. (2015). Hypocrisy by association: When organizational membership increases condemnation for wrongdoing. Organizational Behavior and Human Decision Processes, 130(September), 147-159.

Förster, J., \& Higgins, E. T. (2005). How global versus local perception fits regulatory focus. Psychological Science, 16(8), 631-636.

Förster, J., Higgins, E. T., \& Bianco, A. T. (2003). Speed/accuracy decisions in task performance: Built-in trade-off or separate strategic concerns? Organizational Behavior and Human Decision Processes, 90(1), 148-164.

Gilligan, C. (1982). In a different voice: Psychological theory and women's development. Cambridge, MA: Harvard University Press.

Graham, J., Haidt, J., \& Nosek, B. (2009). Liberals and conservatives use different sets of moral foundations. Journal of Personality and Social Psychology, 96(5), 1029-1046.

Graham, J., Nosek, B. A., Haidt, J., Iyer, R., Koleva, S., \& Ditto, P. H. (2011). Mapping the moral domain. Journal of Personality and Social Psychology, 101(2), 366-385.

Greene, J., \& Haidt, J. (2002). How (and where) does moral judgement work? TRENDS in Cognitive Sciences, 6(12), 517-523.

Griskevicius, V., Goldstein, N. J., Mortensen, C. R., Sundie, J. M., Cialdini, R. B., \& Kenrick, D. T. (2009). Fear and loving in Las Vegas: Evolution, emotion, and persuasion. Journal of Marketing Research, 46(June), 384-395.

Guzmán, F., Paswan, A. K., \& Van Steenburg, E. (2014). Self-referencing and political candidate brands: A congruency perspective. Journal of Political Marketing, 14(1/2), 175-199.

Guzmán, F., \& Sierra, V. (2009). A political candidate's brand image scale: Are political candidates brands? Journal of Brand Manage ment, 17(3), 207-217.

Haidt, J. (2001). The emotional dog and its rational tail: A social intuitionist approach to moral judgment. Psychological Review, 108(4), 814-834.

Haidt, J. (2008). Morality. Perspectives on Psychological Science, 3(1), $65-72$.

Haidt, J., \& Joseph, C. (2004). Intuitive ethics: How innately prepared intuitions generate culturally variable virtues. Daedalus, 133(4), $55-66$.

Hayes, A. F. (2012). PROCESS: A versatile computational tool for observed variable mediation, moderation, and conditional process modeling. White paper.

Higgins, E. T. (1997). Beyond pleasure and pain. American Psychologist, 52(12), 1280-1300.

Higgins, E. T. (1998). Promotion and prevention: Regulatory focus as a motivational principle. Advances in Experimental Social Psychology, 30, 1-46.

Higgins, E. T., Idson, L. C., Freitas, A. L., Spiegel, S., \& Molden, D. C. (2003). Transfer of value from fit. Journal of Personality and Social Psychology, 84(6), 1140-1153.

Hoegg, J., \& Lewis, M. V. (2011). The impact of candidate appearance and advertising strategies on election results. Journal of Marketing Research, 48(5), 895-909.

Huawei (2019, February 19). Should we be worried about the Chinese tech giant? BBC. Accessed 4 March, from, 2019 https:// www.bbc.co.uk/news/business-46465438.

Iyer, R., Koleva, S., Graham, J., Ditto, P., \& Haidt, J. (2012). Understanding libertarian morality: The psychological dispositions of self-identified libertarians. PLOS ONE, 7(8), e42366.

Janoff-Bulman, R., Sheikh, S., \& Hepp, S. (2009). Proscriptive versus prescriptive morality: Two faces of moral regulation. Journal of Personality and Social Psychology, 96(3), 521.

Johnson, E. J., \& Tversky, A. (1983). Affect, generalization, and the perception of risk. Journal of Personality and Social Psychology, 45(1), 20-31.

Kacmar, K., \& Tucker, R. (2014). The moderating effect of supervisor's behavioral integrity on the relationship between regulatory 
focus and impression management. Journal of Business Ethics, 135(1), 87-98.

Komarova Loureiro, Y., Bayuk, J., Tignor, S. M., Nenkov, G. Y., Baskentli, S., \& Webb, D. (2016). The case for moral consumption: Examining and expanding the domain of moral behavior to promote individual and collective well-being. Journal of Public Policy \& Marketing, 35(2), 305-322.

Labroo, A. A., \& Rucker, D. D. (2010). The orientation-matching hypothesis: An emotion-specificity approach to affect regulation. Journal of Marketing Research, 47(5), 955-966.

Laurent, S. M., Clark, B. A., Walker, S., \& Wiseman, K. D. (2014). Punishing hypocrisy: The roles of hypocrisy and moral emotions in deciding culpability and punishment of criminal and civil moral transgressors. Cognition and Emotion, 28(1), 59-83.

Lee, C. J., \& Andrade, E. B. (2011). Fear, social projection, and financial decision making. Journal of Marketing Research, 68, S121-S129.

Lee, J. S., \& Kwak, D. H. (2016). Consumers' responses to public figures' transgression: Moral reasoning strategies and implications for endorsed brands. Journal of Business Ethics, 137(1), 101-113.

Lee, J. S., Kwak, D. H., \& Braunstein-Minkove, J. R. (2016). Coping with athlete endorsers' immoral behavior: Roles of athlete identification and moral emotions on moral reasoning strategies. Journal of Sport Management, 30(2), 176-191.

Lee, J. S., Kwak, D. H., \& Moore, D. (2015). Athletes' transgressions and sponsor evaluations: A focus on consumers' moral reasoning strategies. Journal of Sport Management, 29(6), 672-687.

Lerner, J. S., Gonzalez, R., Small, D., \& Fischhoff, B. (2003). Effects of fear and anger on perceived risks of terrorism: A national field experiment. Psychological Science, 14, 144-150.

Lerner, J. S., \& Keltner, D. (2001). Fear, anger and risk. Journal of Personality and Social Psychology, 81, 146-159.

Luce, M. F. (1998). Choosing to avoid: Coping with negatively emotion laden consumer decisions. Journal of Consumer Research., 24, 409-433.

Luce, M. F., Pavne, J. W., \& Bettman, J. R. (2000). Coping with unfavorable attribute values in choice. Organizational Behavior and Human Decision Processes, 81, 274-299.

Mazar, N., Amir, O., \& Ariely, D. (2008). The dishonesty of honest people: A theory of self-concept maintenance. Journal of Marketing Research, 45(6), 633-644.

Mogilner, C., Aaker, J. A., \& Pennington, G. L. (2008). Time will tell: The distant appeal of promotion and imminent appeal of prevention. Journal of Consumer Research, 34(5), 670-681.

Mullen, E., \& Nadler, J. (2008). Moral spillovers: The effect of moral violations on deviant behavior. Journal of Experimental Social Psychology, 44(5), 1239-1245.

Needham, C., \& Smith, G. (2015). Introduction: Political branding. Journal of Political Marketing, 14(1-2), 1-6.

Newman, B. (2003). Integrity and presidential approval, 1980-2000. The Public Opinion Quarterly, 67(3), 335-367.

Packer, D. J., \& Cunningham, W. A. (2009). Neural correlates of reflection on goal states: The role of regulatory focus and temporal distance. Social Neuroscience, 4(5), 412-425.

Paharia, N., \& Deshpande, R. (2009). Sweatshop labor is wrong unless the jeans are cute: Motivated moral disengagement. Harvard Business School, Harvard Business School Working Papers.

Palanski, M. E., Kahai, S. S., \& Yammarino, F. J. (2011). Team virtues and performance: An examination of transparency, behavioral integrity, and trust. Journal of Business Ethics, 99, 201-216.

Pham, M., \& Avnet, T. (2004). Ideals and oughts and the reliance on affect versus substance in persuasion. Journal of Consumer Research, 30(4), 503-518.
Pham, M., \& Avnet, T. (2009). Contingent reliance on the affect heuristic as a function of regulatory focus. Organizational Behavior and Human Decision Processes, 108(2), 267-278.

Raghunathan, R., \& Pham, M. T. (1999). All negative moods are not equal: Motivational influences of anxiety and sadness on decision making. Organizational Behavior and Human Decision Processes, 79(July), 56-77.

Reynolds, S. J. (2006). Moral awareness and ethical predispositions: Investigating the role of individual differences in the recognition of moral issues. Journal of Applied Psychology, 91, 233-243.

Romani, S., Grappi, S., Zarantonello, L., \& Bagozzi, R. P. (2015). The revenge of the consumer! How brand moral violations lead to consumer anti-brand activism. Journal of Brand Management, $22(8), 658-672$.

Roy, R., \& Phau, I. (2014). Examining regulatory focus in the information processing of imagery and analytical advertisements. Journal of Advertising, 43(4), 371-381.

Schein, C., \& Gray, K. (2018). The theory of dyadic morality: Reinventing moral judgment by redefining harm. Personality and Social Psychology Review, 22(1), 32-70.

Schwabe, M., Dose, D. B., \& Walsh, G. (2018). Every saint has a past, and every sinner has a future: Influences of regulatory focus on consumers' moral self-regulation. Journal of Consumer Psychology, 28(2), 234-252.

Schwartz, S. H. (1977). Normative influences on altruism. In L. Berkowitz (Ed.), Advances in experimental social psychology (pp. 221-279). New York: Academic Press.

Schwarz, N., \& Clore, G. (1983). Mood, misattribution, and judgments of well-being: Informative and directive functions of affective states. Journal of Personality and Social Psychology, 45, 513-523.

Schwartz, S. H., \& Howard, J. A. (1981). A normative decision-making model of altruism. In J. P. Rushton (Ed.), Altruism and helping behaviour: social, personality and developmental perspectives (pp. 189-211). Hillsdale, NJ: Erlbaum.

Shu, L., Gino, F., \& Bazerman, M. H. (2011). Dishonest deed, clear conscience: When cheating leads to moral disengagement and motivated forgetting. Personality and Social Psychology Bulletin, 37(3), 330-349.

Shweder, R. A., Munch, N. C., Mahapatra, M., \& Park, L. (1997). The 'big three' of morality (autonomy, community, and divinity), and the 'big three' explanations of suffering. In A. Brandt \& P. Rozin (Eds.), Morality and health (pp. 119-169). New York: Routledge.

Simons, T. (2002). Behavioral integrity: The perceived alignment between managers' words and deeds as a research focus. Organization Science, 13, 18-35.

Slovic, R. (1987). Perception of risk. Science, 236, 280-285.

Smith, P., \& Trope, Y. (2006). You focus on the forest when you're in charge of the trees: Power priming and abstract information processing. Journal of Personality and Social Psychology, 90, $578-596$.

Spears, N., \& Singh, S. N. (2004). Measuring attitude toward the brand and purchase intentions. Journal of Current Issues and Research in Advertising, 26(2), 53-66.

Starcke, K., Polzer, C., Wolf, O. T., \& Brand, M. (2011). Does stress alter everyday moral decision-making? Psychoneuroendocrinology, 36(2), 210-219.

Steg, L., Dreijerink, L., \& Abrahamse, W. (2005). Factors influencing the acceptability of energy policies: Testing VBN theory. Journal of Environmental Psychology, 25, 415-425.

Stellar, J. E., \& Willer, R. (2018). Unethical and inept? The influence of moral informaitn on perceptions of competence. Journal of Personality and Social Psychology, 114(2), 195-210.

Street-Porter, J. (2018, September 7). Colin Kaepernick had the best intentions for his Nike campaign. Independent. Accessed 10 
October, from, 2018 https://www.cnbc.com/2018/09/12/nikes -kaepernick-ad-drove-away-some-customers-but-galvanized-other s.html.

Sturm, R. E. (2017). Decreasing unethical decisions: The role of morality-based individual differences. Journal of Business Ethics, 142(1), 37-57.

Teper, R., Zhong, C., \& Inzlicht, M. (2015). How emotions shape moral behavior: Some answers (and questions) for the field of moral psychology. Socialand Personality Psychology Compass, 9(1), 1-14.

Thøgersen, J. (2004). A cognitive dissonance interpretation of consistencies and inconsistencies in environmentally responsible behavior. Journal of Environmental Psychology, 24(1), 93-103.

Treviño, L. K., Weaver, G. R., \& Reynolds, S. J. (2006). Behavioral ethics in organizations: A review. Journal of Management, 32(6), 951-990.

Trump, R. K. (2014). Connected consumers' responses to negative brand actions: The roles of transgression self-relevance and domain. Journal of Business Research, 67(9), 1824-1830.

Tweneboah-Koduah, E. Y., Akotia, M., Akotia, C. S., \& Hinson, R. (2010). Political party brand and consumer choice in Ghana. Journal of Management Policy \& Practice, 11(5), 79-88.

Van Den Broek, T., Langley, D., \& Hornig, T. (2017). The effect of online protests and firm responses on shareholder and consumer evaluation. Journal of Business Ethics, 146(2), 279-294.

Van Steenburg, E. (2015). Areas of research in political advertising: A review and research agenda. International Journal of Advertising, 34(2), 195-231.
Walker, L. J. (1989). A longitudinal study of moral reasoning. Child Development, 60(1), 157-166.

Walzer, M. (1978). Teaching morality: Ethics makes a comeback. The New Republic, 178(23), 12-14.

Walzer, M. (1980). The moral standing of states: A response to four critics. Philosophy \& Public Affairs, 9(Spring), 209-229.

Walzer, M. (1983). Spheres of justice: A defense of pluralism and equality. New York: Basic Books.

Wang, J., \& Lee, A. Y. (2006). The role of regulatory focus in preference construction. Journal of Marketing Research, 43(1), 28-38.

Weiss, P. (1942). Morality and ethics. The Journal of Philosophy, 39(14), 381-385.

White, D. W., White, G. L., \& Wilbur, N. (2009). The effects of negative information transference in the celebrity endorsement relationship. International Journal of Retail and Distribution Management, 37(4), 322-335.

Zhu, R., \& Meyers-Levy, J. (2007). Exploring the cognitive mechanism that underlies regulatory focus effects. Journal of Consumer Research, 34(1), 89-96.

Publisher's Note Springer Nature remains neutral with regard to jurisdictional claims in published maps and institutional affiliations. 